\title{
Considerações sobre a Rede de Enfrentamento à Violência Contra as Mulheres
}

\author{
Joyce Duailibe Laignier Barbosa Santos, ${ }^{1}$ Cristina Vianna Moreira dos Santos ${ }^{2}$
}

\begin{abstract}
RESUMO
O objetivo deste artigo é refletir sobre a importância da gestão na articulação da rede no processo de enfrentamento à violência contra as mulheres, buscando informações a respeito dessa temática em estudos bibliográficos, livros e revistas científicas, por meio da metodologia revisão narrativa. Busca-se também, por meio deste estudo, apresentar informações referentes à contextualização da problemática da violência no Brasil, a legislação vigente contra situações de violência e a importância da rede de enfrentamento. A discussão é essencial diante dos inúmeros casos que se apresentam e do crescente fenômeno da violência no cenário nacional. Conclui-se que esse fenômeno complexo e constante deve ser entendido como um problema de saúde pública que exige cada vez mais reflexões aprofundadas e ações efetivas. A proposta não é esgotar o tema, mas trazer uma reflexão à luz de diversos teóricos e uma discussão a respeito da importância da gestão atuante de maneira ativa no processo de enfrentamento à violência contra as mulheres.
\end{abstract}

Palavras-chave: Violência contra a mulher. Violência de gênero. Administração de serviços de saúde. Assistência à saúde.

\section{CONSIDERATIONS ON THE NETWORK FOR COMBATING VIOLENCE AGAINST WOMEN}

\section{ABSTRACT}

This article objective is reflect about the importance of network articulation management in the confront against violence in woman, looking for information about this theme in bibliography studies, books and science journals, by means of the narrative review methodology. It's also sought, through this article, to present information about the challenge of violence in Brazil, the current legislation about violence situations, and confront network importance. The discussion is essential in view of numerous cases present by growing up phenomenon oh violence in the national scene. It is concluded that this complex and constant phenomenon should be understood as a public health problem that requires more and more deeper reflections and effective actions. The proposal isn't to deplete the theme, but take a think with several theorists and a discussion about the importance of active management in the confront against violence in woman process.

Keywords: Violence against women. Gender violence. Health services administration. Health care.

RECEBIDO EM: 21/8/2019

MODIFICAÇÕES SOLICITADAS EM: 19/10/2019

ACEITO EM: 2/7/2020

\footnotetext{
Autor correspondente. Universidade Federal do Tocantins. Quadra 109 Norte, Avenida NS-15, ALCNO-14. Plano Diretor Norte, CEP 77001-090, Palmas/TO, Brasil. http://lattes.cnpq.br/8487935631368681. https://orcid.org/0000-0002-4861-2327. euduailibe@gmail.com

2 Universidade Federal do Tocantins. Miracema do Tocantins/TO, Brasil.
} 


\section{INTRODUÇÃO}

Em meio a tantas transformações sociais, evolução tecnológica, disseminação do respeito pelas diversas culturas, pelas escolhas do outro, respeito ao próximo, a introdução e manutenção da mulher no mercado de trabalho, tornando-se a protagonista de sua própria história, a violência continua sendo um problema social frequente e constante. Falar em violência é ainda um tabu em muitas realidades, no entanto tem-se fomentado socialmente o rompimento da cultura do silêncio, o que gerou o empoderamento da mulher, e de uma rede de enfrentamento que tenta garantir a segurança, apoio e o cuidado da saúde da mulher e de seus filhos (PASSOS, 2010; REZENDE; BARLETTO, 2010; PEREIRA; PEREIRA, 2011).

Souza e Cordeiro (2014) e Waiselfisz (2015) afirmam que a violência contra as mulheres é um fato antigo e constante em nossa sociedade. A novidade encontra-se no fato da visibilidade desse fenômeno, da atuação governamental voltada ao enfrentamento, da criminalização do agressor e da necessidade de superação da violência como condição mínima necessária para a construção de nossa humanidade.

A violência contra as mulheres possui um caráter peculiar, porque, enquanto os homens são vítimas de violência principalmente em espaço públicos, as mulheres, conforme apontam diversas pesquisas, sofrem violência principalmente no âmbito doméstico e familiar, praticado por seus familiares e (ex) companheiros. Dados mostram o impacto das diversas violências sofridas contra as mulheres no Brasil, que podem se enquadrar em violência física, sexual, psicológica, emocional ou moral. Além disso, a violência contra as mulheres, em suas tipologias, atinge diferentes classes sociais, idades, raças e escolaridade, mas, "ainda que seja um fenômeno reconhecidamente presente na vida de milhões de brasileiras, não existem estatísticas sistemáticas e oficiais que apontem para a magnitude deste fenômeno" (BRASIL, 2011a, p. 16), uma vez que muitas mulheres ainda se mantêm caladas por medo ou vergonha, mostrando um cenário nacional com grande número de casos de violência não notificados (BRASIL, 2011a; SOUZA; CORDEIRO, 2014).

É nesse sentido, pensando na relevância social e acadêmica do assunto e na complexidade da violência no contexto brasileiro, que se decidiu escrever sobre essa temática, por entender que as mulheres precisam conquistar cada vez mais espaço e voz. $\mathrm{O}$ objetivo deste artigo é compreender e discorrer sobre a importância da gestão em rede no processo de enfrentamento à violência contra mulheres, buscando informações a respeito dessa temática em estudos bibliográficos, focando principalmente nos serviços de saúde, na contextualização da violência no Brasil e na importância da atuação da gestão. A proposta é essencial diante dos inúmeros casos que se apresentam e do crescente fenômeno da violência no cenário nacional. Muito se fala na conquista de direitos e de espaço, mas enquanto isso não ocorre um grande número de mulheres continua sofrendo e morrendo em decorrência da violência.

\section{MÉTODO}

Este estudo caracteriza-se como uma revisão narrativa, que tem a intenção de entrelaçar saberes e discutir o assunto sob novo enfoque (MARCONI; LAKATOS, 2017). É uma pesquisa bibliográfica, pois o aporte teórico utilizado para o desenvolvimento deste trabalho busca estudar e discutir o tema da violência à luz de diversos autores e referenciais já elaborados, como legislações, livros, artigos, periódicos, entre outros. Na pesquisa em questão, busca-se discutir sobre o fenômeno da violência contra as mulheres no cenário nacional por meio do estudo de diversos teóricos, e de dados estatísticos obtidos em diversas fontes, tais como o Sistema de Informações de Mortalidade (SIM), Ministério da Saúde (MS), a Organização Mundial da Saúde (OMS) e as Secretárias de Vigilância em Saúde (SVS). Por fim, este estudo busca também argumentar a respeito da importância da gestão. A proposta foi traçar um panorama nacional por meio de pesquisa bibliográfica e refletir acerca da importância da gestão, reforçando que a violência é um problema de saúde pública impactante e deve ser tema de constate discussão nas agendas e políticas públicas.

\section{RESULTADOS E DISCUSSÃO}

\section{Contextualizando a violência contra mulheres no Brasil}

A violência foi definida pelo Ministério da Saúde como um fenômeno complexo, polissêmico e controverso (BRASIL, 2001). Já a Organização Mundial da Saúde conceitua violência como

o uso intencional da força física ou do poder, real ou em ameaça, contra si próprio, contra outra pessoa, ou contra um grupo ou uma comunidade, que resulte ou tenha grande possibilidade de resultar em lesão, morte, dano psicológico, deficiência de desenvolvimento ou privação de liberdade $(2002$, p. 5). 
A violência é um termo de conotação negativa, reconhecido como um problema de saúde pública, que perpassa fatores sociais, culturais, políticos e econômicos. É também uma violação dos direitos humanos que tem se tornado preocupação dos governos e aparecido em diversos espaços de discussão. Ainda que qualquer um possa estar no papel de vítima ou agressor, os grupos mais suscetíveis a sofrerem violência são crianças, adolescentes, mulheres, idosos, homossexuais e portadores de deficiência (VILELA, 2009).

Souza e Cordeiro (2014) afirmam que a violência contra a mulher está presente em todas as classes sociais, idades e etnias, e possui um caráter peculiar. Os homens, em grande parte, sofrem violência em espaços públicos, enquanto as mulheres sofrem violência principalmente no âmbito privado, geralmente, em sua maioria, havendo algum tipo de vínculo entre o agressor e a vítima. A respeito das mudanças no processo histórico desse fenômeno, é possível afirmar que:

A violência contra a mulher é referida de diversas formas desde a década de 50. Designada como violência intrafamiliar na metade do século $X X$, vinte anos depois passa a ser referida como violência contra a mulher. Nos anos 80 , é denominada como violência doméstica e, na década de 90 , os estudos passam a tratar essas relações de poder, em que a mulher em qualquer faixa etária é submetida e subjugada, como violência de gênero (BRASIL, 2009, p. 9).

A violência contra a mulher pode acontecer em dois diferentes âmbitos. Na esfera familiar ou doméstica, que pode ser praticada por membros da família ou pessoas com quem a vítima compartilhe um vínculo de afinidade ou afetividade, E na esfera social ou comunitária, por qualquer pessoa ou instituição e em qualquer local (PEREIRA; PEREIRA, 2011).

A Política Nacional de Enfrentamento à Violência Contra a Mulher prevê quatro eixos para trabalhar as questões da violência contra a mulher por meio do enfrentamento: combate, prevenção, assistência e garantia dos direitos (BRASIL, 2011b). A Lei 11.340/2006 (Lei Maria da Penha) é um marco reconhecido da luta das mulheres contra a violência, e traz em seu texto a conceituação de violência e suas diferentes tipologias.

A violência física compreende atos que ofendem a integridade ou saúde corporal da mulher, entendida essencialmente como agressão corporal. A violência psicológica constitui-se de atos de ameaça, humilhação, constrangimento, isolamento, limitação de direitos, perseguição e outras ações ou omissões que causem prejuízo à saúde psicológica e ao desenvolvimento pessoal. A violência sexual é entendida como a obrigação de presenciar ou participar de relação sexual não desejada; coação ao matrimônio, gravidez, aborto ou exploração sexual; é a anulação dos direitos sexuais e reprodutivos e da liberdade de decidir sobre sua sexualidade e sobre a utilização de métodos contraceptivos. A violência patrimonial consiste em reter, subtrair, destruir parcial ou totalmente objetos, instrumentos de trabalho, documentos pessoais, bens, valores e direitos ou recursos econômicos. A violência moral traduz-se em condutas que representam calúnia, difamação ou injúria e são definidos como crimes contra a honra (BRASIL, 2006; PASSOS, 2010; PEREIRA; PEREIRA, 2011).

Minayo (2006) argumenta que a violência contra a mulher, de modo geral, acontece nas relações de poder que os homens exercem sobre as mulheres e pela opressão de gênero. É um problema social que perpassa diferentes classes, raças e idades; distintos espaços familiares e públicos e diferentes épocas, visto que atitudes de violência se manifestam já há bastante tempo na História.

Waiselfisz (2015) contextualizou as violências contra mulheres cometidas no Brasil por meio de um mapa da violência. A primeira vez que surgiu a necessidade de se trabalhar a violência especificamente contra a mulher foi em 2012, quando o Estado percebeu que os dados apresentavam números expressivos. Os estudos resultaram num mapa da violência contra a mulher publicado em 2012. Um novo estudo foi publicado em 2015, com dados comparativos entre 1980 e 2013-2014, trazendo estudos sobre homicídios baseados no Sistema de Informações de Mortalidade (SIM) e sobre violências notificadas, baseado no Sistema de Informação de Agravos de Notificação (Sinan).

De acordo com o autor, entre 1980 e 2013 o aumento do número de mulheres vítimas de homicídio foi de $252 \%$, alterando a taxa de 2,3 para 4,3 vítimas por 100 mil habitantes. Waiselfisz (2015) afirma ainda que após criação da Lei Maria da Penha, em 2006, os números tiveram uma queda significativa nos anos seguintes, voltando a aumentar em 2009. Segundo dados da OMS, o Brasil constava em 5 o lugar entre os países com maior taxa de feminicídios entre 83 países.

Com relação à raça, Waiselfisz (2015) afirma que de modo geral a taxa de homicídios de mulheres negras tende a ser maior que o de mulheres brancas. No comparativo de idade, o autor afirma que a faixa etária com maior índice de homicídios é entre 18-30 
anos, além da elevada incidência de infanticídio. Ainda baseado em dados de 2013, com relação aos meios utilizados para homicídio, os mais comuns são: armas de fogo, totalizando $48 \%$, objetos cortantes ou perfurantes, totalizando $25,3 \%$, objetos contundentes $8,0 \%$, e estrangulamento, $6,1 \%$ contra mulheres, havendo ainda $11,8 \%$ incluídos na opção "outros".

O estudo traz também dados de violência não letal, obtidos por meio do Sinan. Waiselfisz (2015) afirma que em 2014 no Brasil o atendimento a mulheres que foram vítimas de violência supera o atendimento a homens na faixa etária entre 0-60 anos. Após os 60 anos, os atendimentos se distribuem de forma aleatória. Ainda nesse mesmo ano, para as jovens e adultas entre 18 e 59 anos de idade, o principal agressor é o parceiro ou ex-parceiro, concentrando a metade de todos os casos registrados, seguidos de violência autoprovocada e de violência por parte de parentes imediatos (pais, filhos, irmãos e tios). A respeito dos tipos de violência com maior incidência aparecem a violência física em primeiro lugar, totalizando $48 \%$, a psicológica com 23\% e a sexual representando 11,9\% dos casos notificados em 2014. No que se refere ao local de ocorrência da violência, o autor constatou que no ano de $201471,9 \%$ dos casos contra mulheres ocorreram em residência, seguidos de 15,9\% nas ruas. É importante ressaltar que os casos de violência notificados indicam maior ocorrência no âmbito doméstico, enquanto os dados apresentados sobre homicídio assinalam maior índice de mortes de mulheres nas vias públicas.

Já os dados obtidos pelo Ligue 180 revelam que a faixa etária que mais entrou em contato com o serviço foram mulheres entre 20 e 40 anos, que possuem majoritariamente Ensino Fundamental completo ou incompleto e convivem com o agressor por 10 anos ou mais e possuem vínculo afetivo, totalizando $74 \%$ dos crimes denunciados por esse canal. Os dados mostram também que " $38 \%$ das mulheres sofrem violência desde o início da relação e 60\% delas relataram que as ocorrências de violência são diárias; e que $66 \%$ dos filhos presenciam a violência e $20 \%$ sofrem violência junto com a mãe" (BRASIL, 2011a, p. 17).

De acordo com Waiselfisz (2015), as taxas de homicídio de mulheres no Tocantins cresceram $67,7 \%$ no comparativo entre os anos 2006 e 2013, ocupando o 9o lugar entre os 27 Estados da Federação. Na capital, Palmas, nesse mesmo período as taxas aumentaram $951,6 \%$, ficando como a primeira capital com maior crescimento da porcentagem das taxas de homicídio de mulheres por 100 mil habitantes.
O Relógio da Violência é uma iniciativa do Instituto Maria da Penha que se pauta em estudos do Fórum Brasileiro de Segurança Pública, realizado em 2017, para trazer dados alarmantes a respeito dos índices de violência contra as mulheres no Brasil. Pautado nos parâmetros da pesquisa, o Relógio da Violência afirma que: a cada 2 segundos uma mulher é vítima de violência verbal ou física; a cada 6,9 segundos uma mulher é vítima de perseguição; a cada 2 minutos uma mulher é vítima de arma de fogo; a cada 22,5 segundos uma mulher é vítima de espancamento ou tentativa de estrangulamento; a cada 1,4 segundo uma mulher é vítima de assédio. Essas e outras informações estão disponíveis no site eletrônico do Relógio da Violência (FÓRUM..., 2017).

Waiselfisz (2015, p. 51) afirma que a violência contra as mulheres é "mais sistemática e repetitiva do que a que acontece contra os homens. Esse nível de recorrência da violência deveria ter gerado mecanismos de prevenção, o que não parece ter acontecido" no Brasil da forma como é necessário. Enfrentar o fenômeno da violência requer ações articuladas que englobam diferentes atores sociais. A violência contra a mulher exige a mobilização de recursos e disponibilização de serviços em tempo integral, o que requer uma rede integrada de atenção, funcionando de forma interligada (VILELA, 2009).

\section{Legislação e articulação de políticas públicas no Brasil}

No processo histórico de conquista das mulheres, muitas lutas aconteceram para o avanço do espaço adquirido. Simone de Beauvoir, mulher influente que escreveu livros sobre a condição feminina nos anos 40 do século 20, afirmava que diante de qualquer crise política, econômica ou religiosa, os direitos das mulheres seriam questionados. Os direitos adquiridos infelizmente não são permanentes, por isso as mulheres precisam estar vigilantes durante todo o tempo, sempre lutando em prol de melhorias e manutenção daquilo que já foi conquistado. Historicamente, as mulheres começaram a buscar o voto na Inglaterra em 1897, mas só conseguiram adquirir esse direito a partir de 1918. Em março de 1911 aconteceu um grande incêndio na fábrica Triangle Shirtwaist Company, em Nova York, que marcou a luta e morte de mais de 120 mulheres em busca de direitos trabaIhistas e redução da jornada de trabalho. A luta por melhorias aconteceu por meio de diversas manifestações em várias partes do mundo. $O$ incêndio na Triangle, entre outros, foi um dos grandes marcos históricos que instituiu e consagrou o dia 8 de março como 
o Dia Internacional da Mulher (BLAY, 2001). No Brasil em 1827 as mulheres conquistaram o direito de frequentar as escolas e centros educacionais, e em 1879 o direito de frequentar instituições de ensino superior. Em 1928 as mulheres lutam pelo direito ao voto e vão às ruas, mas os votos femininos são anulados. Apenas em 1932 é que esse direito é finalmente garantido às mulheres brasileiras. Em 1945 a Carta das Nações Unidas reconhece internacionalmente a igualdade de direitos entre homens e mulheres, e em 1951, a Organização Internacional do Trabalho propõe a igualdade salarial entre homens e mulheres (MOREIRA, 2016, SOUZA; CORDEIRO, 2014).

O movimento feminista que se iniciou a partir de 1980 trouxe uma nova perspectiva a problemas que antes não eram considerados relevantes no cenário político. Entre muitas bandeiras levantadas pelos movimentos da época, a luta contra a violência doméstica e a percepção de que a violência era um problema político foram reforçadas. Um fenômeno antes muito presente na sociedade, mas ainda invisível, começou a ganhar espaços de discussão (MOREIRA, 2016). Segundo Souza e Cordeiro (2014), em 1985 foi criada a primeira Delegacia Especial de Atendimento à Mulher, que reforçou o debate sobre a violência e institucionalizou o atendimento para casos antes omissos. Nesse contexto é importante citar também a Constituição Federal de 1988, que representou a redemocratização do país e influenciou no avanço das discussões sobre os direitos das mulheres e na igualdade de gênero.

Em 2003 foi criada a Secretaria de Políticas para as Mulheres, com o objetivo de fortalecer as políticas públicas de enfrentamento à violência contra as muIheres. Até aquele momento, as ações voltadas ao enfrentamento da violência se constituíam de capacitação de profissionais nas redes de atendimento e da criação de serviços especializados. A partir da criação da Secretaria, as políticas públicas são ampliadas e passam a incluir ações integradas, tais como a "criação de normas e padrões de atendimento, aperfeiçoamento da legislação, incentivo à constituição de redes de serviços, apoio a projetos educativos e culturais de prevenção à violência e ampliação do acesso das muIheres à justiça e serviços de segurança pública" (BRASIL, 2011a, p. 9).

É significativo citar nessa sequência histórica a criação da lei 9.099 de 2005, que alterou o termo "réu" para "acusado", e substituiu as penas de privação de liberdade por penas de menor potencial ofensivo (geralmente multa, entrega de cestas básicas ou prestação de serviços comunitários). A lei, além de morosa e ineficaz, em casos de violência doméstica fragilizava a situação da vítima, porque dava liberdade ao agressor mesmo após a denúncia e julgamento (PASSOS, 2010).

A lei no 11.340, de 7 de agosto de 2006, também conhecida como Lei Maria da Penha, foi um marco no cenário brasileiro. Isso porque foi a primeira lei criada especificamente para coibir a violência doméstica e familiar contra a mulher, além de definir os atos de violência como crimes de maior punição, não cabendo apenas pagamento de multa ou serviço comunitário (BRASIL, 2011a; MOREIRA, 2016). Ainda a respeito dessa lei, outras conquistas incluem a ampliação da atividade da polícia, a proibição da colaboração da vítima na notificação do agressor (o que incentivava a ocorrência de novos episódios de violência), a conceituação dos tipos de violência e suas diferentes formas de manifestação, "a proibição da aplicação de penas pecuniárias aos agressores; e a determinação de encaminhamentos das mulheres em situação de violência, assim como de seus dependentes, a programas e serviços de proteção e de assistência social" (BRASIL, 2011a, p. 20).

O Pacto Nacional pelo Enfrentamento à Violência contra as Mulheres foi instituído em 2007, partindo da perspectiva de que a violência é um fenômeno multidimensional, e que, para combatê-lo, são necessárias políticas públicas amplas e articuladas. O objetivo principal é "enfrentar todas as formas de violência contra as mulheres a partir de uma visão integral deste fenômeno" (BRASIL, 2011a, p. 26), e assegurar a prevenção e o combate à violência, além da assistência e garantia de direitos. A proposta traz quatro eixos estruturantes, que são: 1 . Implementação da Lei Maria da Penha e Fortalecimento dos Serviços Especializados de Atendimento; 2. Proteção dos Direitos Sexuais e Reprodutivos e Implementação do Plano Integrado de Enfrentamento da Feminização da Aids; 3 Combate à Exploração Sexual e ao Tráfico de Mulheres e 4. Promoção dos Direitos Humanos das Mulheres em Situação de Prisão O Pacto apoia-se nos princípios da transversalidade de gênero, na intersetorialidade e na capilaridade (BRASIL, 2011a).

A transversalidade de gênero visa a garantir que a questão de violência contra a mulher e de gênero perpasse as mais diversas políticas públicas setoriais. A intersetorialidade, por sua vez, compreende ações em duas dimensões: uma envolvendo parcerias entre organismos setoriais e atores em cada esfera de governo (ministérios, secretarias, coordenadorias, etc.); e outra que implica uma maior articulação entre políticas nacionais e locais em diferentes áreas (saúde, justi- 
ça, educação, trabalho, segurança pública, etc.). Desta articulação decorre a terceira premissa que diz respeito à capilaridade destas ações, programas e políticas; levando a proposta de execução de uma política nacional de enfrentamento à violência contra as mulheres até os níveis locais de governo (BRASIL, 2011a, p. 24).

O Pacto citado é respaldado pelos 10 e 20 Planos Nacionais de Política para Mulheres, lançados respectivamente em 2004 e 2008. Os Planos descrevem estratégias de prevenção e combate à violência e de assistência e garantia de direitos. 0 10 Plano estruturou a Política Nacional de Enfrentamento à Violência contra as Mulheres, que mais tarde culminou no Pacto já descrito. Este Plano representou uma mudança da percepção do Estado com relação à violência, fazendo com que o governo se mostrasse mais atuante e responsável pelas formas de combate à violência e à desigualdade de gênero e raça. 0 20 Plano foi criado a partir da mobilização de mulheres em conferências nacionais e municipais e é bem mais amplo, contando com 11 áreas de atuação que definem diversas metas, prioridades e ações (SOUZA; CORDEIRO, 2014).

Em 2013 foi lançado o programa "Mulher, Viver sem Violência", criado pelo governo federal por meio do Decreto no 8.086, de 30 de agosto daquele ano, e que propõe a ampliação e integração dos serviços já existentes voltados ao enfrentamento da violência contra a mulher. A ideia da proposta é articular os serviços de diferentes instâncias, como promoção de saúde, justiça, segurança pública e assistência social. O Programa foi proposto pelo Estado do Paraná, e 26 unidades da Federação (com exceção de Pernambuco) assinaram o termo de adesão. O Programa é composto pelos seguintes eixos: 1. Implementação da Casa da Mulher Brasileira; 2. Ampliação da Central de Atendimento à Mulher - Ligue 180; 3. Organização e Humanização do Atendimento às Vítimas de Violência Sexual; 4. Instituição E Manutenção Dos Centros De Atendimento Às Mulheres Nas Regiões De Fronteira Seca; 5. Campanhas Continuadas de Conscientização e 6. Unidades Móveis Para Atendimento A Mulheres Em Situação De Violência No Campo E Na Floresta (BRASIL, 2015b).

A Casa da Mulher Brasileira, que é um dos eixos do Programa, começou a ser instituída em 2015, e surgiu como uma proposta inovadora que busca facilitar o acesso aos serviços e disponibilizar um atendimento humanizado às mulheres em situação de violência. De acordo com as diretrizes do Programa, o objetivo é facilitar o acesso "aos serviços especializados para garantir condições de enfrentamento da violência, o empoderamento da mulher e sua autonomia econômica. É um passo definitivo do Estado para o reconhecimento do direito de as mulheres viverem sem violência" (BRASIL, 2015b, p. 14). Os serviços incluem acolhimento e triagem, apoio psicossocial, vínculo com a Delegacia Especializada de Atendimento à MuIher (Deam), com Juizados e Varas especializadas em violência contra a mulher, Promotoria e Defensoria Pública, auxílio no deslocamento de mulheres para os serviços, acolhimento de crianças que acompanham essas mulheres, alojamento temporário de mulheres que estão em situação de risco e disponibilidade de outros serviços de saúde. Atualmente a Casa da MuIher Brasileira está em funcionamento nos municípios de Campo Grande (MS), São Luís (MA), Curitiba (PR) e Brasília (DF) (BRASIL, 2015b).

A lei 13.104, sancionada em 9 de março de 2015, conhecida como Lei do Feminicídio, incluiu essa modalidade de homicídio no rol de crimes hediondos e com agravantes em situações de vulnerabilidade (BRASIL, 2015a). É entendido como feminicídio "a agressão que envolve violência doméstica e familiar, ou quando evidencia menosprezo ou discriminação à condição de mulher, caracterizando crime por razões de condição do sexo feminino" (WAISELFISZ, 2015, p. 7).

\section{A rede de enfrentamento à violência contra as mulheres}

A rede de enfrentamento à violência contra as mulheres diz respeito à atuação articulada entre diversos aparatos institucionais (governamentais e não governamentais), de serviços especializados e não especializados e da comunidade. A proposta é buscar estratégias de prevenção contra a violência e empoderamento das mulheres. Nesse sentido, trabalha-se também a responsabilização dos agressores, a autonomia da mulher, a assistência transdisciplinar e a garantia e acesso a seus direitos. A rede de enfrentamento apresenta-se dividida em quatro eixos norteadores: combate, prevenção, assistência e garantia de direitos (BRASIL, 2011b).

O âmbito do combate é voltado principalmente a ações punitivas e incentivo ao cumprimento da Lei Maria da Penha; a prevenção foca-se nas ações educativas e culturais; o eixo da assistência busca fortalecer a rede de atendimento e incentivar a capacitação de profissionais e o eixo da garantia de direitos está voltado ao cumprimento das legislações nacionais e ao empoderamento feminino (BRASIL, 2011b).

O eixo da assistência é o espaço no qual existem mais ações e mais participação ativa dos diversos setores. Está dividido em quatro áreas: saúde, justiça, 
segurança pública e assistência social. Este eixo é executado por meio da rede de atendimento, que faz parte da rede de enfrentamento e se refere a um conjunto de serviços, em setores diferenciados, que buscam ampliar a qualidade no atendimento, humanizar os serviços ofertados e disponibilizar encaminhamentos de forma adequada (BRASIL, 2011b).

A fim de esclarecer a diferença entre redes de atendimento e enfrentamento, a cartilha da Secretaria Especial de Políticas para as Mulheres traz o seguinte quadro:

Quadro 1 - Características da Rede de Enfrentamento e da Rede de Atendimento às Mulheres em Situação de Violência

\begin{tabular}{|cc|}
\hline Rede de Enfrentamento & Rede de Atendimento \\
\hline $\begin{array}{c}\text { Contempla todos os eixos } \\
\text { da Política Nacional }\end{array}$ \\
$\begin{array}{c}\text { (combate, prevenção, } \\
\text { assistência e garantia de } \\
\text { direitos). }\end{array}$ & $\begin{array}{c}\text { Refere-se somente ao eixo } \\
\text { da assistência/atendimento. }\end{array}$ \\
\hline $\begin{array}{c}\text { Inclui órgãos responsáveis } \\
\text { pela gestão e controle social } \\
\text { das políticas de gênero, } \\
\text { além dos serviços de } \\
\text { atendimento. }\end{array}$ & $\begin{array}{c}\text { Restringe-se a serviços de } \\
\text { atendimento (especializados } \\
\text { e não especializados). }\end{array}$ \\
\hline $\begin{array}{c}\text { É mais ampla que a rede de } \\
\text { atendimento às mulheres em } \\
\text { situação de violência. }\end{array}$ & $\begin{array}{c}\text { Faz parte da rede de } \\
\text { enfrentamento à violência }\end{array}$ \\
\hline
\end{tabular}

Fonte: Cartilha Rede de Enfrentamento à Violência contra as muIheres, Brasil, 2011b.

A rede deve funcionar de forma articulada, mas toda a divisão é feita de forma didática, a fim de definir e apresentar à população o funcionamento dos serviços da maneira mais simples e clara, e também para organizar os setores, distribuir as metas e obter informações mais precisas. Desse modo, afirma-se que

a rede de enfrentamento à violência contra as mulheres é marcada, portanto, pela multiplicidade de serviços e de instituições. Esta diversidade deve ser compreendida como parte de um processo de construção que visa abarcar a multidimensionalidade e a complexidade da violência contra as mulheres. Todavia, para que o enfrentamento da violência se efetive, é importante que serviços e instituições atuem de forma articulada e integrada (BRASIL, 2011b, p. 16).

Nesse mesmo sentido Olivieri (2003) afirma que as redes têm o propósito de unir pessoas e organizações de maneira democrática e participativa, com objetivos pariformes. O funcionamento em rede indi- ca que os participantes são colaborativos e mantêm-se em relações horizontais, movidos por uma causa significativa que une diferentes grupos. A rede deve ser flexível e aberta, e "trabalhar a potencialidade dos sujeitos e suas ações [e discussões]; otimizar os recursos; obter maiores impactos de resultados; ampliar o poder nas negociações e construir trabalhos em parcerias" (SOUZA; CORDEIRO, 2014, p. 94).

$A$ rede de atendimento pondera que a mulher em situação de violência tem várias portas de entrada, que devem estar organizadas para receber, realizar o primeiro acolhimento e os encaminhamentos para a rede conforme cada situação (BRASIL, 2011b). Para isso é necessário que, em cada um dos serviços, haja profissionais habilitados para o manejo de situações de violência e capacitados para o atendimento e o primeiro contato com a vítima (VILELA, 2009). As quatro áreas da rede de atendimento - saúde, justiça, segurança pública e assistência social - abarcam todos os serviços que podem ser acessados como porta de entrada à rede. A área da saúde abrange os postos de saúde, hospitais, serviços especializados de atendimentos a vítimas de violência sexual, serviços voltados ao tratamento de saúde mental, o Programa de Saúde da Família (PSF) e o Serviço de Atendimento Móvel de Urgência (Samu). Os setores da Justiça englobam os Juizados Especiais, Defensorias, Promotorias, Ministério Público e Centros de Reabilitação do Agressor. A área da segurança inclui as Delegacias e Postos Especializados, a Polícia Civil, bombeiros e o Instituto Médico Legal (IML). A área da assistência social compreende serviços como o Centro de Referência de Assistência Social (Cras), o Centro de Referência Especializado de Assistência Social (Creas), as Casas-Abrigo e o Disque 180 (Central de Atendimento à MuIher) (BRASIL, 2011b).

Existem alguns desafios que interferem no funcionamento da rede de forma efetiva. Um deles está relacionado à dificuldade em estabelecer um fluxo de informações claro sobre os serviços. Muitas vezes os profissionais de determinado serviço não são capazes de realizar os encaminhamentos corretamente em decorrência da falta de conhecimento das funções de cada instituição que compõe a rede de atenção. Nesse sentido, algumas organizações oferecem atendimento multidisciplinar, mas não repassam o andamento dos processos com a vítima aos demais serviços, o que acaba por gerar lacunas entre instâncias que deveriam trabalhar integradas (SOUZA; CORDEIRO, 2014). Outra problemática está na qualidade do atendimento prestado por alguns profissionais, que não estão habilitados para trabalhar com situações de violência, e que 
chegam a culpabilizar a vítima, que não conseguem ter empatia ou um olhar mais humanizado para a fragilidade do outro. Existem profissionais que assumem uma postura investigativa "fazendo perguntas exaustivas e desnecessárias, desrespeitando a intimidade e a privacidade da vítima da violência. Em determinados casos busca-se, inclusive, justificar e explicar a violência sofrida tendo como parâmetro o comportamento da vítima" (FRIEDRICH, 2016, p. 205).

Outra problemática levantada por Grossi et al. (2012, p. 269) é que

muitas mulheres podem não procurar o atendimento em decorrência da violência que estão sofrendo, pelo fato destas não se reconhecerem enquanto vítimas, acreditando ser esta uma relação natural e/ou normal, especialmente se estas convivem no seu dia a dia com alguns valores que reproduzem a ideia da mulher submissa e do homem poderoso. O estabelecimento de uma relação de confiança e vínculo é fundamental para a revelação da violência.

Os desafios compreendem também problemas de subnotificação da violência; do silêncio da vítima e de pessoas próximas, evitando falar sobre as agressões por medo, vergonha ou crença de que a situação irá mudar; a inexistência de um sistema único de registro e análise de dados estatísticos, visto que cada área de atendimento possui dados divergentes (a Delegacia registra um quantitativo de atendimentos diferente do registrado pelo Disque 180, que é também distinto dos registrados em serviços de saúde, etc.); a insuficiência de investimento em serviços já existentes e em serviços novos, em capacitação e qualificação profissional e em políticas públicas que alcancem toda a população, posto que ainda hoje muitas muIheres sofrem caladas por desconhecimento dos seus direitos e da rede de apoio e pela falta de empoderamento, que só pode ser desenvolvido em um ambiente seguro e confiável (CARREIRA; PANDJIARJIAN, 2003; SOUZA; CORDEIRO, 2014; FRIEDRICH, 2016).

O papel da gestão na articulação da rede de enfrentamento à violência contra as mulheres

O gestor é o profissional que está à frente de uma equipe ou instituição, e deve zelar pela missão, visão e pelos valores da organização. "Gestores têm uma participação significativa no que se refere aos rumos do sistema de saúde, já que participam das decisões tomadas e têm sob seu comando os profissionais que prestam cuidados à população" (PAULA JUNIOR, 2013, p. 12).
A violência contra mulheres é um fato comprovado em nossa sociedade, e interfere cotidianamente na saúde e bem-estar da população feminina. A rede de enfrentamento é uma proposta que busca "dar conta da complexidade da violência contra as mulheres e do caráter multidimensional do problema, que perpassa diversas áreas, tais como: a saúde, a educação, a segurança pública, a assistência social, a justiça, a cultura, entre outros" (BRASIL, 2011b, p. 8). Tendo em vista que a violência configura um fenômeno que tem tomado proporções extremamente significativas é que os gestores devem estar atentos e capacitados para compreender e conduzir as organizações, no sentido de possibilitar acolhimento humanizado e atendimento integrado aos demais serviços que sejam necessários à vítima (PAULA JUNIOR, 2013).

Paula Junior (2013) apresentou alguns estudos realizados com gestores em diferentes regiões do Brasil que apontam quais são, na percepção deles, os maiores entraves para o trabalho em rede na área da violência. De acordo com a pesquisa, a precariedade e disputa de recursos para investimento, as dificuldades com capacitação e formação de profissionais, fragmentação dos processos de trabalho evidenciados na falta de articulação e integração dos serviços que compõem a rede de atendimento, ineficiência dos encaminhamentos e fragilidades institucionais, deficiência de uma intervenção eficaz no atendimento à vítima estão entre os problemas mais recorrentes.

Grossi et al. (2012, p. 276) trazem uma importante percepção acerca de como o trabalho em rede deve funcionar. Conforme os autores, "entre os desafios está a materialização dos pressupostos de trabaIho em rede como a horizontalidade e o enfrentamento das relações de poder existentes entre diferentes políticas e setores". Trabalhar essas questões seria, talvez, uma proposta inicial para a resolução dos diversos problemas abordados pelos gestores.

O trabalho em rede implica trabalhar na perspectiva da horizontalidade, realizando mediações entre o particular e o universal e lidando com correlações de forças. Compreende buscar estratégias para mobilizar potencialidades nos sujeitos a fim de confrontar as forças que o fragilizam. Em relação à rede de enfrentamento à violência contra mulheres, isto demanda a identificação das potências e estratégias de resistência por parte das mulheres que lutam contra todas as formas de opressão que subalternizam e desqualificam suas identidades (GROSSI et al., 2012, p. 273). 
Outras sugestões mais urgentes que devem partir dos gestores para o fortalecimento da rede estão relacionadas à ampliação e consolidação da rede de serviços especializados de atendimento a mulheres em situação de violência e à capacitação de profissionais dos serviços especializados e da Rede de Atendimento (BRASIL, 2013). Além disso, os gestores devem ser capazes de compreender a formulação e instauração de políticas e programas de saúde e articular as decisões relativas ao sistema de saúde, na perspectiva integral, com as necessidades e anseios dos profissionais, avaliando ainda os agravos mais comuns em sua região e as possíveis alternativas para melhoria da qualidade de vida da população (PAULA JUNIOR, 2013).

Porto et al. (2003) ressaltam que é primordial que os gestores sejam capazes de perceber a violência contra a mulher como um problema de saúde pública, com sérias consequências em curto e longo prazos. Os autores evidenciam também que as questões de gênero precisam ser incorporadas mais intensamente nas políticas públicas de saúde, capacitando profissionais para o acolhimento e escuta ativa e abrindo espaço para o diálogo e a elaboração coletiva de soluções articuladas e definitivas, capazes de romper com o fenômeno da violência.

\section{CONSIDERAÇÕES FINAIS}

A partir das discussões apresentadas é possível inferir que, apesar da violência ser um fenômeno antigo, a sua percepção contra a mulher como um problema de saúde pública é ainda bastante recente. Desse modo, é essencial entendermos a complexidade e multicausalidade deste fenômeno, as definições e tipificações da violência contra a mulher e diversidade pelas quais ela poder ser expressa.

A rede de enfrentamento à violência contra as mulheres representa a consolidação das políticas públicas para a população feminina, conquistada por meio de diversas mobilizações e movimentos. Configura-se como um avanço histórico que aponta para o cumprimento das leis e do respeito à vida. É evidente que há ainda muito a avançar, considerando que a rede de enfrentamento à violência apresenta lacunas e fragilidades em seu processo de articulação e integração de serviços, uma vez que muitos destes funcionam de forma isolada.

Então, apesar das conquistas alcançadas, entende-se que muitas mudanças fazem-se necessárias para efetivar a proposta do funcionamento em rede. Nesse sentido, torna-se urgente o desenvolvimento de estratégias de atendimento e acolhimento de qua- lidade à vítima e também ao agressor, que devem ser disponibilizadas nos diversos serviços que compõem a rede de enfrentamento. Além disso, é essencial o desenvolvimento de políticas de promoção e prevenção, com a finalidade de minimizar os avanços das situações de violência. Essas mudanças só serão possíveis mediante o envolvimento das diferentes instâncias que compõem a rede de enfrentamento para superação dos limites e desafios, fortalecimento de estratégias, organização dos serviços e fluxos e o funcionamento satisfatório da rede e suas dimensões.

Compreender a perspectiva dos gestores que estão à frente dos serviços que integram a rede de enfrentamento à violência contra a mulher é extremamente importante. Isso porque quem faz a gestão é parte essencial do processo de fortalecimento dessa rede e da resolução de problemas enfrentados nas diferentes dimensões que a compõem. Para romper com os estigmas e silêncio da violência enfrentada diariamente pelas mulheres faz-se necessário atuação intensa dos gestores em três frentes: a situação da violência em si deve ser ampliada em espaços de discussão, de modo a minimizar os julgamentos às vítimas e incentivar o empoderamento (principalmente porque é comum o discurso de medo de denunciar porque pode ser agredida novamente ou por vergonha). Fazem parte desse contexto também questões relacionadas à orientação ao agressor e à família que convive com a violência e a vulnerabilidade dos profissionais, que têm receio de notificar ou de questionar a vítima diante ou próximo ao agressor. Outra frente seria o comprometimento da comunidade nessas discussões. Nesse sentido, incluir essa temática nas escolas e universidades e propor políticas de prevenção e promoção de saúde envolvendo a população é essencial no processo de enfrentamento às situações e violência. Por fim, outra frente seria o envolvimento ativo dos governos, políticos e gestores do sistema de saúde, de modo a fomentar capacitações dos profissionais, investir em estrutura e organização de serviços, recursos, etc., e também dos gestores de outras instâncias e instituições, no intuito de fazer funcionar a rede de atendimento em todo seu potencial, integrando de fato os diversos setores da saúde, justiça, assistência social e segurança pública. Desse modo, fica clara a urgente necessidade da atuação em diferentes âmbitos para possibilitar a efetivação da proposta da rede de enfrentamento, compreendendo que apenas por meio da movimentação em diferentes frentes será possível modificar a realidade das situações de violência. 


\section{REFERÊNCIAS}

BLAY, E. A. 8 de março: conquistas e controvérsias. Rev. Estud. Fem, Florianópolis, v. 9, n. 2, 2001.

BRASIL. Lei no 11.104/2005. Lei do Feminicídio. Brasília, 2015a.

BRASIL. Lei no 11.340/2006. Lei Maria da Penha. Brasília, 2006.

BRASIL. Ministério da Saúde. Atenção Integral para Mulheres e Adolescentes em Situação de Violência Doméstica e Sexual: matriz pedagógica para formação em redes. Brasília, 2009.

BRASIL. Ministério da Saúde. Direitos humanos e violência intrafamiliar: informações e orientações para agentes comunitários de saúde. Brasília, 2001.

BRASIL. Pacto Nacional pelo Enfrentamento à Violência Contra as Mulheres. Secretaria de Políticas para as Mulheres. Secretaria Nacional de Enfrentamento à Violência Contra as Mulheres. Brasília, 2011a.

BRASIL. Programa Mulher, Viver sem Violência: diretrizes gerais e protocolos de atendimento. Secretaria de Enfrentamento à Violência Contra as Mulheres. Paraná, 2015b.

BRASIL. Rede de enfrentamento à violência contra as muIheres. Secretaria Nacional de Enfrentamento à Violência Contra as Mulheres. Brasília, 2011b.

BRASIL. Secretaria Especial de Políticas para as Mulheres. Plano Nacional de Políticas para Mulheres 2013-2015. Brasília, 2013.

CARREIRA, D.; PANDIIARJIAN, V. Vem pra roda! Vem pra rede!: Guia de apoio à construção de redes de serviços para o enfrentamento da violência contra a mulher. São Paulo: Rede Mulher de Educação, 2003.

FÓRUM BRASILEIRO DE SEGURANÇA PÚBLICA. Instituto Maria da Penha. Relógio da Violência. Visível e invisível: a vitimização de mulheres no Brasil. Brasil, 2017.

FRIEDRICH, S. A. G. O atendimento terapêutico às vítimas de violência sexual no município de São José dos Pinhais/ PR: experiência de implantação do ambulatório sentinela. In: Tempus, Actas de Saúde Colet., Brasília, 10(1), p. 195210, mar, 2016.

GIL, A. C. Métodos e técnicas de pesquisa social. 6. ed. São Paulo: Atlas, 2008.

GROSSI, P. K. et al. Prevenção da violência contra mulheres: desafios na articulação de uma rede intersetorial. In: Athenea Digital, 12(3), p. 267-277, nov. 2012.

GUIMARÃES, M. C.; PEDROZA, R. L. S. Violência contra a mulher: problematizando definições teóricas, filosóficas e jurídicas. In: Psicologia \& Sociedade, 27(2), p. 256-266, 2015.

MARCONI, M. A.; LAKATOS, E. M. Fundamentos de metodologia científica. 8. ed. São Paulo: Atlas, 2017.

MINAYO, C. S. M. Violência e saúde. Rio de Janeiro: Fiocruz, 2006 (Série Temas em Saúde).
MOREIRA, L. A. Direito e gênero: a contribuição feminista para a formação política das mulheres no processo de (re) democratização brasileiro. In: Periódico do Núcleo de Estudos e Pesquisas sobre Gênero e Direito Centro de Ciências Jurídicas, Universidade Federal da Paraíba, v. 5, n. 1, 2016.

OLIVIERI, L. A importância histórico-social das redes - Rede de informações para o terceiro. In: EnANPAD, XXXI, Rio de Janeiro, 2003. Anais... Rio de Janeiro: Anpad, 2003, p. 1-17. OMS. Organização Mundial da Saúde. Relatório mundial sobre violência e saúde. Genebra, 2002.

PASSOS, H. R. Conhecendo a Rede de Apoio à Mulher Vítima de Violência do Município de Belo Horizonte. Belo Horizonte: Universidade Federal de Minas Gerais, UFMG, 2010.

PAULA JUNIOR, G. V. Crenças de gestores de saúde em relação à violência doméstica. 2013. Dissertação (Mestrado) - Universidade de Juiz de Fora, Minas Gerais, 2013.

PEREIRA, M. N. C.; PEREIRA, M. Z. C. A Violência doméstica contra a mulher. In: Espaço do Currículo, v. 4, n. 1, p. 22-34, mar./set. 2011.

PORTO, M. et al. A saúde da mulher em situação de violência: representações e decisões de gestores/as municipais do Sistema Único de Saúde. In: Cad. Saúde Pública, Rio de Janeiro, 19(Sup. 2), p. S243-S252, 2003.

REZENDE, D. L.; BARLETTO, M. A rede de enfrentamento à violência contra a mulher no município de Viçosa, Minas Gerais. In: SEMINÁRIO INTERNACIONAL FAZENDO GÊNERO, 9., Diásporas, Diversidades, Deslocamentos. Florianópolis, 23 a 26 ago. 2010.

SOUZA, V. M. C. S.; CORDEIRO, R. L. M. Os desafios das redes de enfrentamento á violência doméstica no Recife. In: Rev. Ciências Humanas e Sociais, Recife, v. 1, n. 3, p. 91-109, 2014.

TOJAL, A. L. S. et al. Rede de enfrentamento à violência contra a mulher: situação dos serviços especializados no município de Maceió. In: Revista Brasileira de Tecnologias Sociais, v.3, n.2, 2016.

VILELA, L. F. (coord). Secretaria de Estado de Saúde do Distrito Federal. Manual para Atendimento às Vítimas de Violência na Rede de Saúde Pública do Distrito Federal. 2a ed. Brasília, 2009.

WAISELFISZ, J. J. Mapa da violência 2015: homicídio de muIheres no Brasil. Brasília, 2015. 